Supplement of Arch. Anim. Breed., 62, 375-382, 2019

https://doi.org/10.5194/aab-62-375-2019-supplement

(C) Author(s) 2019. This work is distributed under

the Creative Commons Attribution 4.0 License.

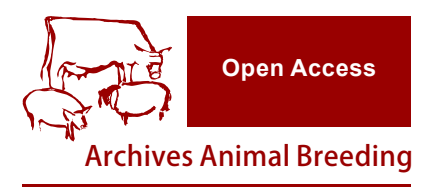

(c) (1)

Supplement of

\title{
DNA methylation of the PLIN1 promoter downregulates expression in chicken lines
}

Yuhang Sun et al.

Correspondence to: Yuxiang Wang (wyx2000@ neau.edu.cn)

The copyright of individual parts of the supplement might differ from the CC BY 4.0 License. 


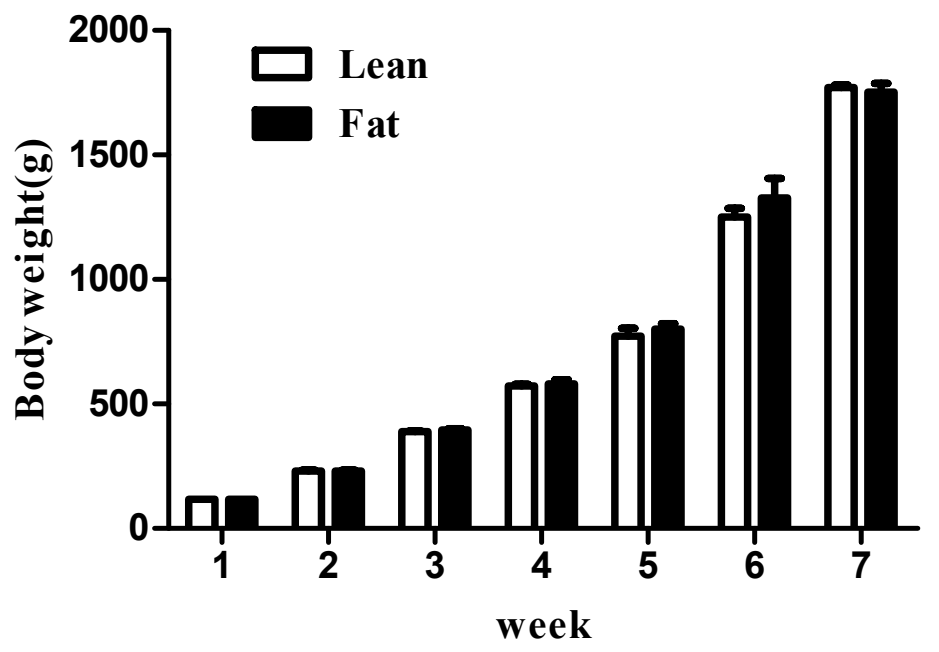

